\title{
A METHOD OF ESTIMATING CALCIUM CARBONATE IN SOILS.
}

\author{
By HERBERT S. SHREWSBURY, F.I.C.
}

(Read at the Meeting, March 6, 1912.)

Methods of estimating calcium carbonate in soils depending on the measurement of carbon dioxide evolved from the carbonates by absorption or otherwise have not been found very satisfactory; the modified method proposed by F. S. Marr (J. Agricultural Science, 1909, 3, 155) appears to give good results, but is somewhat lengthy, and entails rather special apparatus and skilful manipulation for its successful application.

An alternative method which I have devised depends upon the extraction of the calcium carbonate from the soil in $\frac{\mathrm{N}}{4}$ acetic acid, the conversion of the calcium acetate so formed into calcium oxide and its solution in $\frac{N}{10}$ acetic acid, and the titration of the excess of acid required by the lime with $\frac{\mathrm{N}}{10}$ potash or soda, using phenolphthalein as an indicator.

Ten grms. of finely divided air-dried soil are placed in a dry wide-mouthed flask or bottle, and 100 c.c. of approximately $\frac{N}{4}$ acetic acid are added. For a period of ten minutes the flask is shaken with a rotary movement every time the bulk of the soil settles, which occurs about every thirty seconds. The soil is then allowed to settle for the last time, and the liquid contents of the flask decanted through a dry filter. Schleicher and Schüll's filter cones answer the purpose admirably. A control experiment is made with another 10 grms. of soil, using distilled water as the extracting solvent. Twenty-five c.c. of each filtrate are evaporated to dryness in a platinum dish, and ignited at a bright red heat for thirty minutes, the residues when cool being treated with 10 c.c. of $\frac{\mathrm{N}}{10}$ acetic acid (or more if necessary). Solution is effected in a few minutes, particularly if the residues are gently rubbed with a glass rod tipped with a small rubber bung.

The excess of acid is then titrated with $\frac{\mathrm{N}}{10}$ soda or potash, using phenolphthaleïn as indicator. The volume obtained from the control is now subtracted from that obtained from the acid extraction of the soil, and the result multiplied by 0.2 . The product gives the percentage of calcium carbonate in the soil.

Notes on the Process.-The quantities given will answer for soils containing up to 5 per cent. of calcium carbonate, which covers the usual range. For larger percentages proportionate amounts of soil are taken. The time and method of extraction were based on experiments made with pure calcium carbonate and $\frac{N}{4}$ acetic acid.

Some soils appear to retain a portion of the calcium acetate, presumably by reason of a greater concentration of the solution occurring in immediate contact with the soil particles. The occasional error due to a soil of this type does not appear to be large enough to warrant a complete washing of the soil, an operation which is lengthy and tedious.

The purpose of the control is to measure alkaline carbonates and alkaline organic salts, soluble organic calcium salts, calcium nitrate, or any bodies which are 
soluble in water, and which on ignition leave an alkaline residue soluble in $\frac{N}{10}$ acetic acid. One-tenth c.c. of $\frac{N}{10}$ acid was the maximum obtained in this titration for three soils that were examined. $\frac{\mathrm{N}}{\mathrm{i} \sigma}$ acetic acid is chosen for the solution of the residues because it does not dissolve ignited iron oxide, whilst easily attacking calcium oxide.

It is preferable to measure the calcium oxide by titration rather than to weigh it or estimate it by conversion into oxalates and comparison of the turbid liquid with standards, since the first mothod excludes other salts of calcium than the carbonate, with the possible exception of organic calcium salts insoluble in water but soluble in $\frac{N}{4}$ acetic acid. It is desirable to make qualitative tests on the same volumes of the acetic acid extract of the soil for the presence of calcium and magnesium chlorides and sulphates.

Frequently the last three are only present in traces.

If the amount of magnesium is comparatively large, it may be quickly estimated by the method given by Thresh ("Examination of Water and Water-Supplies," p. 238), depending on the comparison of the precipitate obtained with sodium hydrogen phosphate (after removal of calcium with ammonium hydrate and ammonium oxalate), when shaken up in a certain volume of water, with standards prepared in the same way. The magnesium estimated would of course include any salt of magnesium soluble in $\frac{\mathrm{N}}{4}$ acetic acid, but in most soils the error introduced would be insignificant.

The following table sets out the results of test experiments, made with the process on soils prepared with known percentages of calcium carbonate. The sample of precipitated chalk used for this purpose was analysed, and found to contain practically 100 per cent. of calcium carbonate :

\begin{tabular}{c|c|c|c|c}
\hline & \multicolumn{3}{|c}{ Per Cent. Calcium Carbonate in Soil. } \\
\cline { 2 - 5 } Sample of Soil. & $\begin{array}{c}\text { Originally } \\
\text { Present. }\end{array}$ & Added. & Total. & $\begin{array}{c}\text { Found by } \\
\text { Process. }\end{array}$ \\
\hline $\begin{array}{c}\text { A. Surface soil from soft } \\
\text { ferruginous shale ... }\end{array}$ & 0.07 & 0.05 & 0.12 & 0.13 \\
$\begin{array}{c}\text { B. Heavy clay subsoil previ- } \\
\text { ously treated with hot } \\
\text { concentrated hydro- } \\
\text { chloric acid for twelve } \\
\text { hours, washed, and } \\
\text { dried in steam-oven }\end{array}$ & Nil & 0.50 & 0.50 & 0.50 \\
$\begin{array}{c}\text { C. Clay subsoil ... ... } \\
\begin{array}{c}\text { D. Clay subsoil ... ... } \\
\text { D. }\end{array}\end{array}$ & 0.29 & 0.50 & 0.79 & 0.61 \\
\hline
\end{tabular}

Government Laboratory, Trinidad, B. W.I. 